\title{
Encephalitozoonosis (nosematosis) causing bilateral cataract in a rabbit
}

\author{
NORMAN ASHTON, CHARLES COOK, AND FRANCIS CLEGG \\ From the Department of Pathology, Institute of Ophthalmology, University of London, and \\ Ministry of Agriculture, Fisheries and Food, Loughborough, Leicestershire
}

Encephalitozoonosis, first described by Wright and Craighead (1922), is a chronic disease of rodents being a common and usually latent condition in many colonies of rabbits with a prevalence of 15 to 76 per cent (Pakes, 1974); it has been reported in a wild rabbit. It is caused by a microsporidan parasite Encephalitozoon cuniculi, the name given by Levaditi, Nicolau, and Schoen (1923). References to its identification, taxonomy, and pathology are to be found in the reviews of Petri (1969) and Pakes (1974). This parasite has also been described in blue foxes (Kangas, 197I; Kull, 197I ; Nordstoga, 1972), in dogs (Plowright, 1952; Basson, McCully, and Warnes, 1966), and in the cat and the ox (Schuster, 1925), although in the last cases the organism was not definitely identified. Only two acceptable cases of systemic infection in man have been reported (Matsubayashi, Koike, Mikata, Takei, and Hagiwara, 1959; Margileth, Strano, Chandra, Neafie, Blum, and McCully, 1973).

In 1964 it was believed that Encephalitozoon belonged to the family Nosematidae and it was proposed that the organism affecting mammals be re-named Nosema cuniculi (Wieser, 1964; Lainson, Garnham, Killick-Kendrick, and Bird, 1964). Recent studies, however, by Cali (1971), Shadduck and Pakes (1971), and Sprague and Vernick (1971), comparing the microsporidium with the type species for the genus Nosema (that is, Nosema bombycis - the cause of silkworm disease) have revealed differences in the developmental cycle. A return to the original name Encephalitozoon cuniculi was, therefore, proposed.

The only published case of infection of the animal eye is that of Perrin (1943) who found lymphocytic infiltration and a single accumulation of parasites in the retina of a spontaneously infected rat. A solitary case of such infection in the human eye was reported by Ashton and Wirasinha (1973) who found microsporidia in a corneal disc removed for a penetrating keratoplasty in an I I-year-old boy from Ceylon.

Address for reprints: Professor N. Ashton, FRS, Department of Pathology, Institute of Ophthalmology, Judd Street, London $\mathrm{WCIH}_{9 \mathrm{QS}}$
The purpose of the present communication is to report the first known example of cataract due to encephalitozoonosis, which occurred bilaterally in a spontaneously infected laboratory rabbit.

\section{Material and findings}

Bilateral cataract in a five-month-old rabbit (New Zealand white male; one of a litter of eight born 5 May 1975) was first noted by one of us (FGC, in connexion with an investigation not relevant here) and the animal was sent for further examination to the Department of Pathology at the Institute of Ophthalmology, London. No cataracts were observed ophthalmoscopically in the seven litter mates: the eyes of four of these submitted for histology showed no abnormality.

\section{CLINICAL EXAMINATION}

\section{Right eye}

The lens appeared clear apart from a triangular white opacity in the anterior cortex at 12 o'clock. No posterior synechiae or distortion of the pupil were seen and there was no other abnormality.

\section{Left eye}

Nodular fluffy white masses were seen within the anterior lens cortex at 4 and 8 o'clock, and posterior synechiae adjacent to these areas distorted the pupil. No other abnormality was seen.

\section{HISTOLOGY}

\section{Macroscopical examination}

The eyes were opened coronally and the anterior segments examined in normal saline at room temperature under the stereoscopic microscope. The findings confirmed the clinical examination (Figs $I$ and 5). No other abnormalities were observed either in the anterior or posterior segments. The right anterior segment was sectioned in paraffin, while the left anterior segment and both posterior segments were sectioned in celloidin.

\section{Microscopical examination}

Right eye : anterior segment

The predominant pathological changes were to be seen in the lens which showed a focal cortical cataract on one 


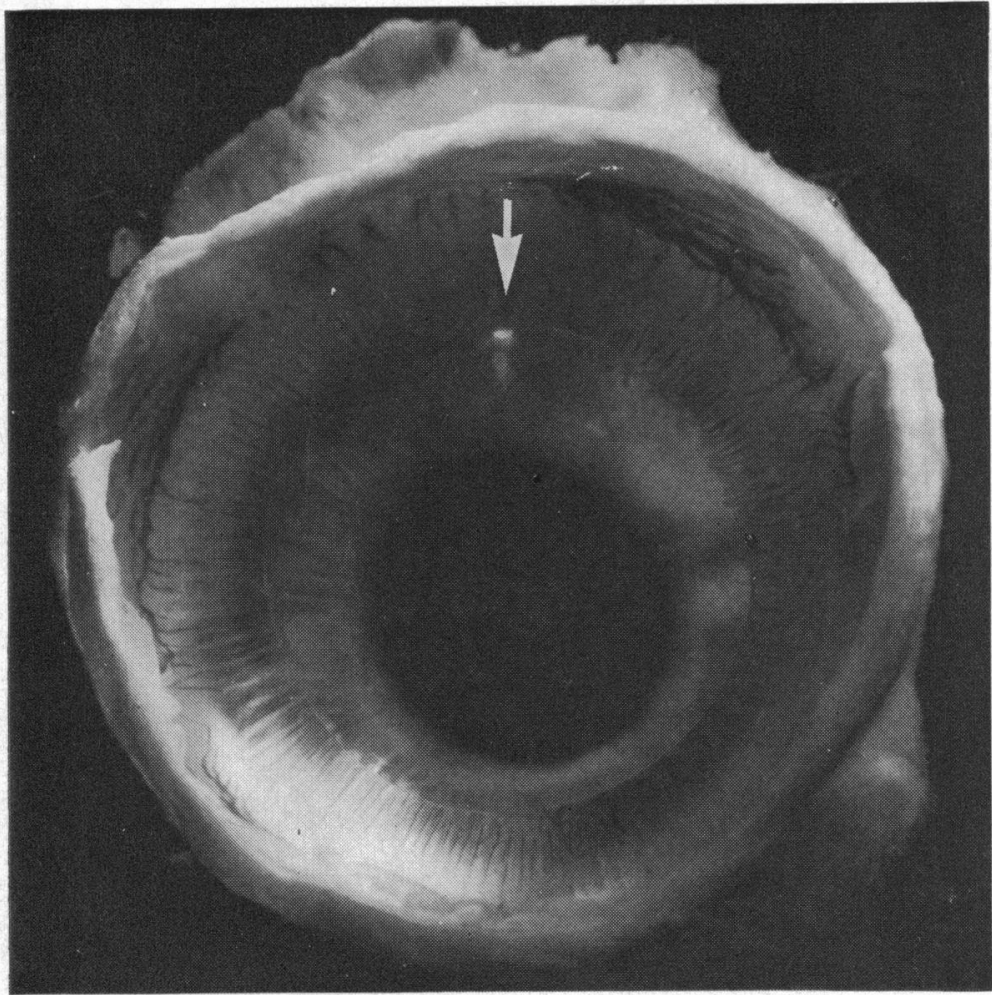

FIG. I Right eye. Anterior segment, viewed postero-anteriorly. $A$ triangular white opacity is seen at 12 o'clock (arrow) within anterior cortex of lens

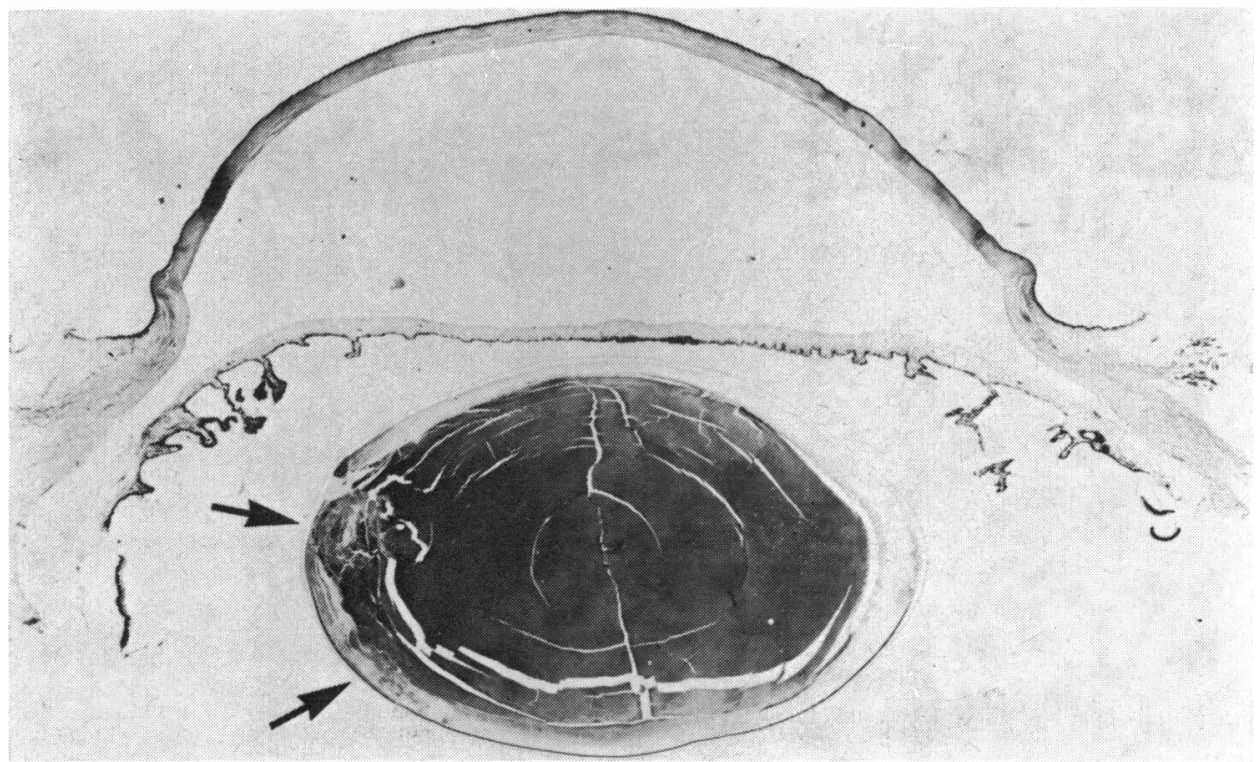

FIG. 2 Right eye. Section of anterior segment. Arrows indicate site of cortical invasion by microsporidia. Note inflammatory infiltration of adjacent ciliary processes compared with unaffected processes on opposite side. Haematoxylin and eosin. $\quad \times 9$ 


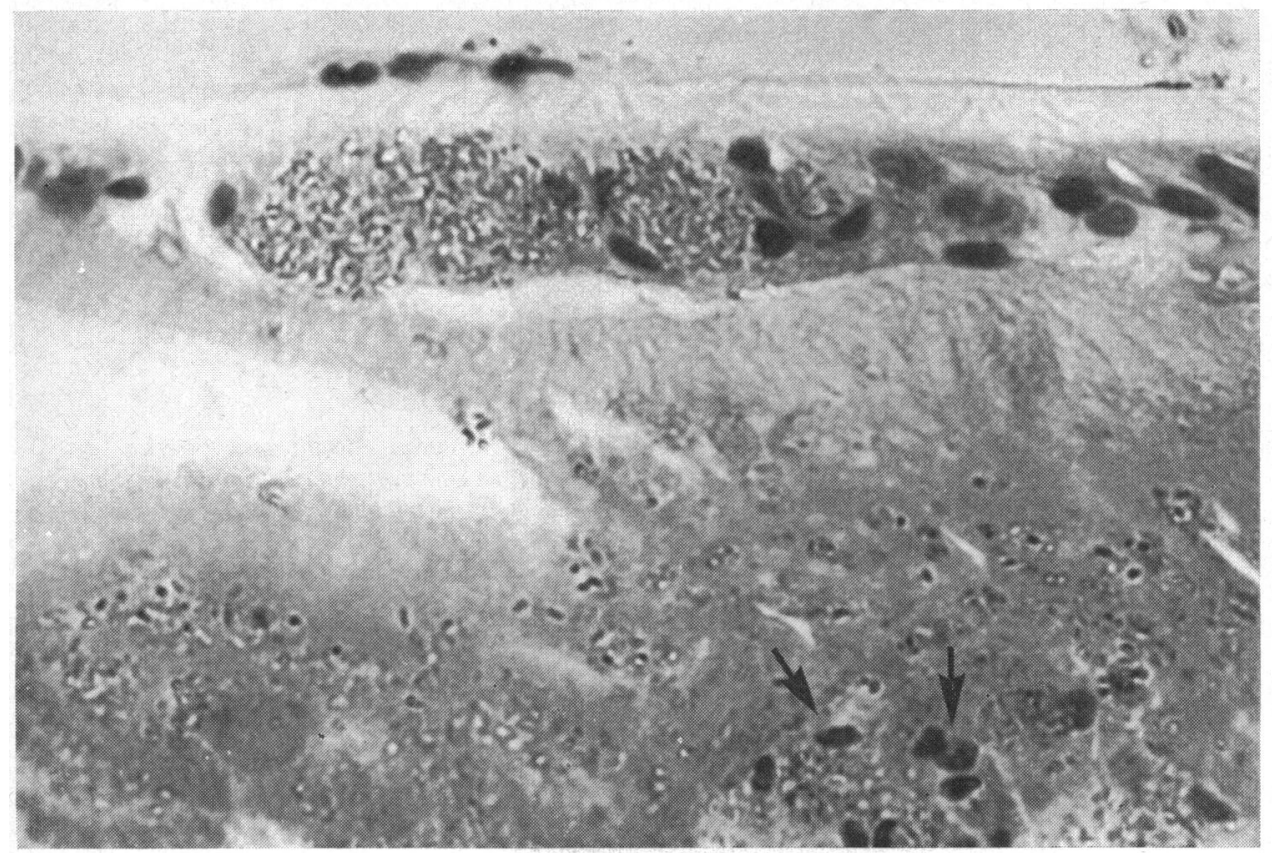

FIG. 3 Right eye. Equatorial region of lens showing numerous refractile microsporidan spores within lens epithelium and lying free in adjacent cataractous cortical tissue together with degenerate epithelial nuclei (arrows). A few inflammatory cells are seen on surface of intact lens capsule. Haematoxylin and eosin. $\times 780$

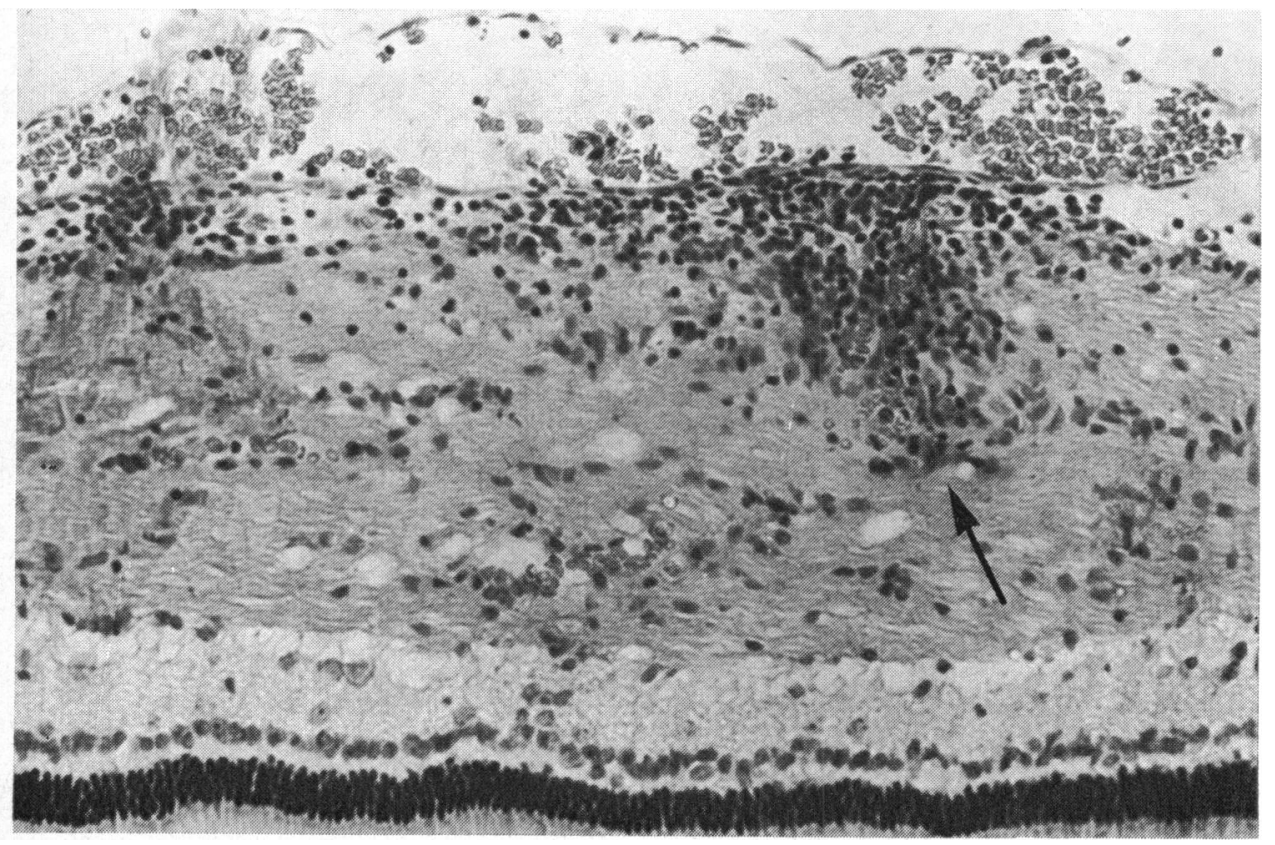

FIG. 4 Right eye. Posterior segment showing a focal infiltration of monocytes in relation to a surface vessel and its intraretinal branch (arrow). No microsporidia were found outside lens. Haematoxylin and eosin. $\times 260$ 


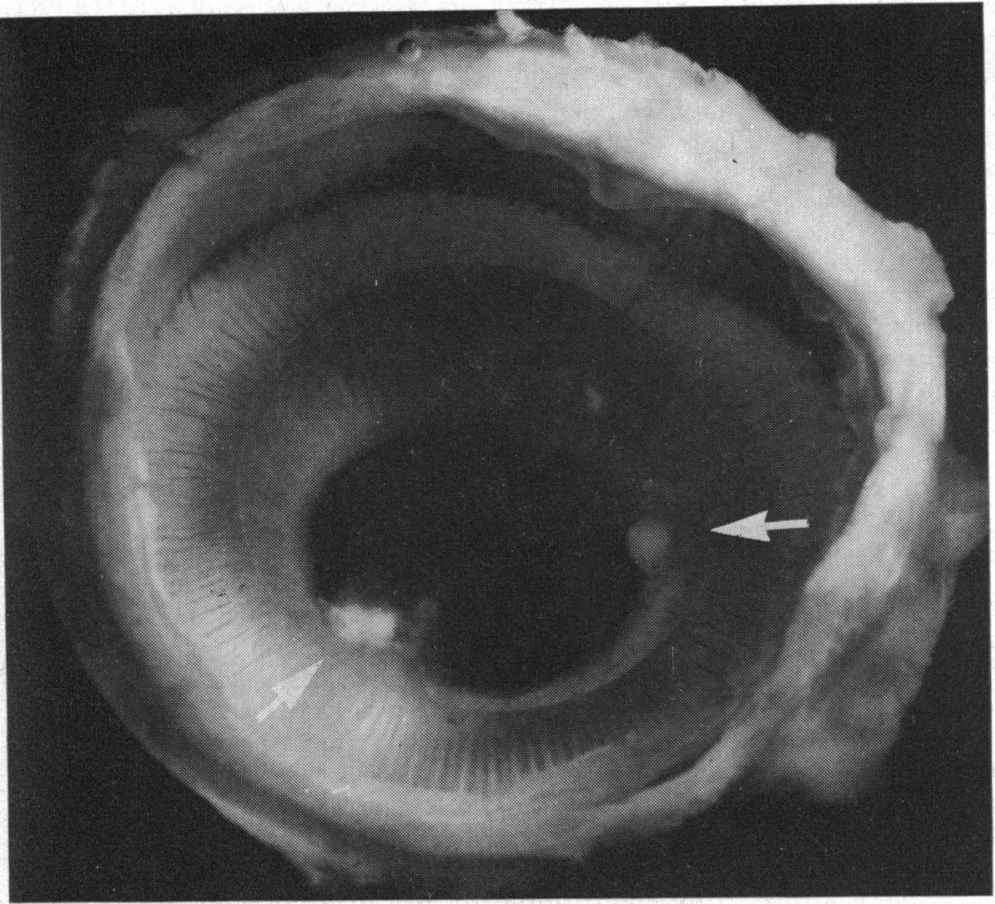

FIG. 5 Left eye. Anterior segment, viewed postero-anteriorly. Nodular fluffy white masses are seen at 4 and $8 o^{\prime}$ 'clock within anterior cortex of lens (arrows)

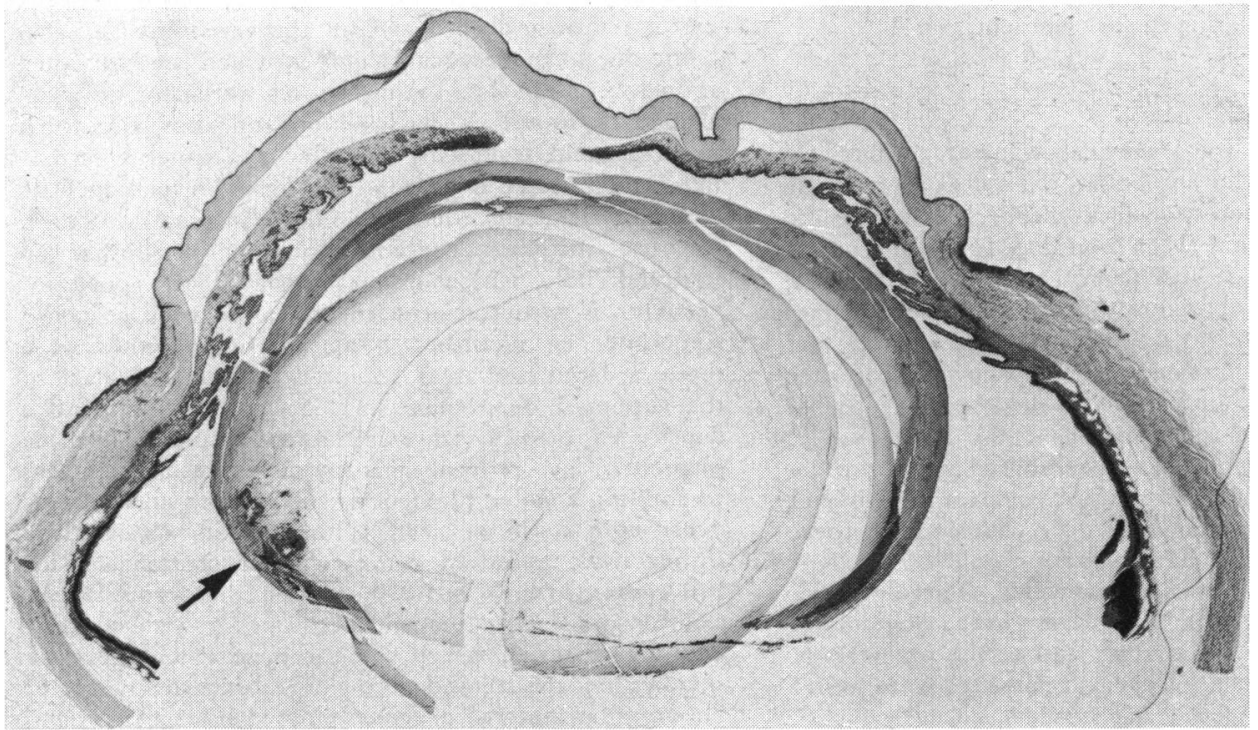

FIG. 6 Left eye. Section of anterior segment showing masses of microsporidia in lens cortex at equator on one side (arrow). Other lesions towards nucleus are not seen at this level. Haematoxylin and eosin. $\times 9.5$ 
side of the section only and particularly at the equator, where several epithelial cells showed cytoplasmic aggregations of microsporidan parasites with highly refractile capsules and basophilic contents. These parasites were also seen within the cataractous equatorial tissue in irregular masses or lying free in eosinophilic fluid intermingled with degenerating epithelial nuclei. The adjacent ciliary body showed an intense inflammatory reaction extending into the posterior chamber. There was, however, only a mild inflammatory infiltration of the iris, and the ciliary body on the opposite side was almost normal. Only mononuclear cells were seen in the inflammatory reaction; there were no neutrophils or eosinophils and no parasites could be found outside the lens capsule (Figs 2 and 3 ).

\section{Special stains}

Periodic acid-Schiff and celestin blue failed to stain the organisms and no anterior polar cap could be identified. No breaks were found in the lens capsule in the region of the invaded epithelium. Giemsa and Gram stains gave variable results suggesting that some of the organisms were degenerate. Silver methenamine (Grocott-Gomori) stain showed masses of brownishblack microsporidia apparently empty.

\section{Right eye : posterior segment}

This showed a focal infiltration of monocytic cells on the surface of the disc and in the inner layers of the retina, especially around the surface vessels and intraretinal branches (Fig. 4). The choroid was normal except at the peripapillary margin where there was a mild inflammatory infiltration. In one minute focus in the retina posteriorly there was a sharply demarcated area of visual cell atrophy. No microsporidan parasites were found in any tissue in this segment.

\section{Left eye: anterior segment}

The lens showed focal cortical cataract particularly evident in the anterior and equatorial cortex on one side where masses of microsporidia could be seen within the liquefied lens material (Figs 6 and 7). In some sections they were associated with necrotic inflammatory cells, including a few polymorphonuclears, which had invaded the lens at two points where the capsule had ruptured (Fig. 8). Some sections showed parasites situated equatorially in relation to degenerate epithelial cell nuclei without inflammatory cells. Additionally, isolated granular aggregates resembling microsporidia were seen throughout the anterior cortex and near and within the lens nucleus (Fig. 9); occasionally these masses were calcified. The posterior pole of the lens was not invaded by cells or parasites. There was an inflammatory reaction in the anterior uvea, particularly intense at the pupillary margin and at the ora serrata. As in the case of the right eye, no parasites were found outside the lens.

\section{Special stains}

Periodic acid-Schiff and haematoxylin (PASH) stain showed basophilic nucleoplasm but no periodic acidSchiff-positive reaction; periodic acid-Schiff and celestin blue and toluidine blue showed no specific staining of the microsporidia. Giemsa and Gram stains showed refractile capsules with blue contents, but the staining was variable. Silver methenamine (Grocott-Gomori) stain provided the best method for demonstrating the parasites; they stained black and were associated with crystalline debris (Fig. 10).

\section{Left eye : posterior segment}

This showed essentially similar changes to those of the right eye.

\section{ELECTRON MICROSCOPY}

A ro $\mu \mathrm{m}$ celloidin section from the left lens was lightly stained with haematoxylin and examined in water under a dissecting microscope. The affected area containing the parasites was dissected out with micro-instruments and the celloidin was removed, the specimen rehydrated, postfixed in I per cent buffered osmium tetroxide, processed, and embedded in epoxy-resin. Thick flat sections were cut, using an LKB ultrotome 3, stained with toluidine blue and areas were selected for thin sectioning. These sections were examined with a Joel JEM $100 \mathrm{C}$ electron microscope. A diagram illustrating the known ultrastructure of a microsporidan spore is shown in Fig. II.

Electron micrographs showed large numbers of thickly encapsulated structures containing degenerate electron-dense material and an even larger number of thinly encapsulated cells resembling respectively mature and immature microsporidan spores lying in a coarsely granular matrix containing irregular homogeneous masses (Fig. 12). The mature spores ranged between $2.8 \times \mathrm{I} \cdot \mathrm{I} \mu \mathrm{m}$ and $\mathrm{I} .6 \times 0.8 \mu \mathrm{m}$, this variability probably being due to the level and angle at which the individual spores were cut. The mature spores were oval, commashaped or round in cross-section and showed a thick electron-lucid wall with an outer and inner electrondense membrane. Because of the formalin fixation little could be definitely identified in the internal structure, but the shrunken contents occasionally showed an irregular hole which might represent the posterior vacuole. A structure resembling a polaroplast could sometimes be identified lying anteriorly either as a dense or laminated area. An anterior vacuole in place of the supposed polaroplast was occasionally seen and a dense area, possibly the nucleus (sporoplasm, germ, or plamont), lay centrally. In some parasites profiles resembling a coiled filament or tubule with an electrondense core could be seen. The sporonts appeared as simple oval, round or comma-shaped structures with thick membrane-bound homogeneous moderately electron-dense contents and occasionally with coarsely granular material, which sometimes extruded into the surrounding matrix and might have been the source of the granular material previously noted (Figs 13,14 , and I5).

It must be emphasized that the poor fixation and degenerative nature of this tissue makes a certain diagnosis impossible. Moreover, vacuoles of the order 


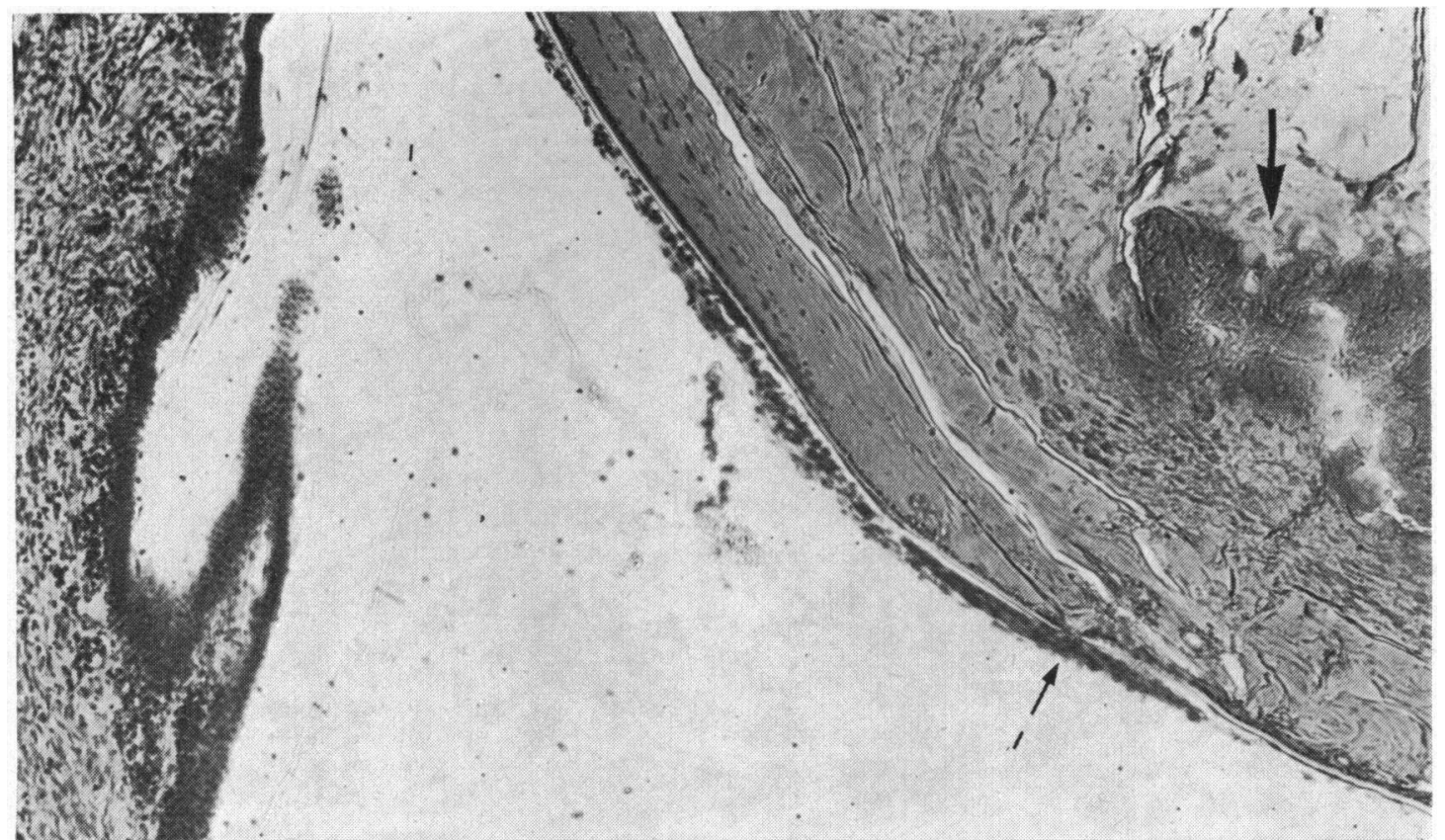

FIG. 7 Left eye. Anterior segment. A mass of microsporidia lies within cataractous cortex of equatorial lens (thicker arrow) and inflammatory cells cover lens capsule which shows a small rupture (thinner arrow). $A$ monocytic inflammatory reaction is present in ciliary body and inflammatory cells are scattered throughout posterior chamber. Haematoxylin and eosin. $\quad \times 72$

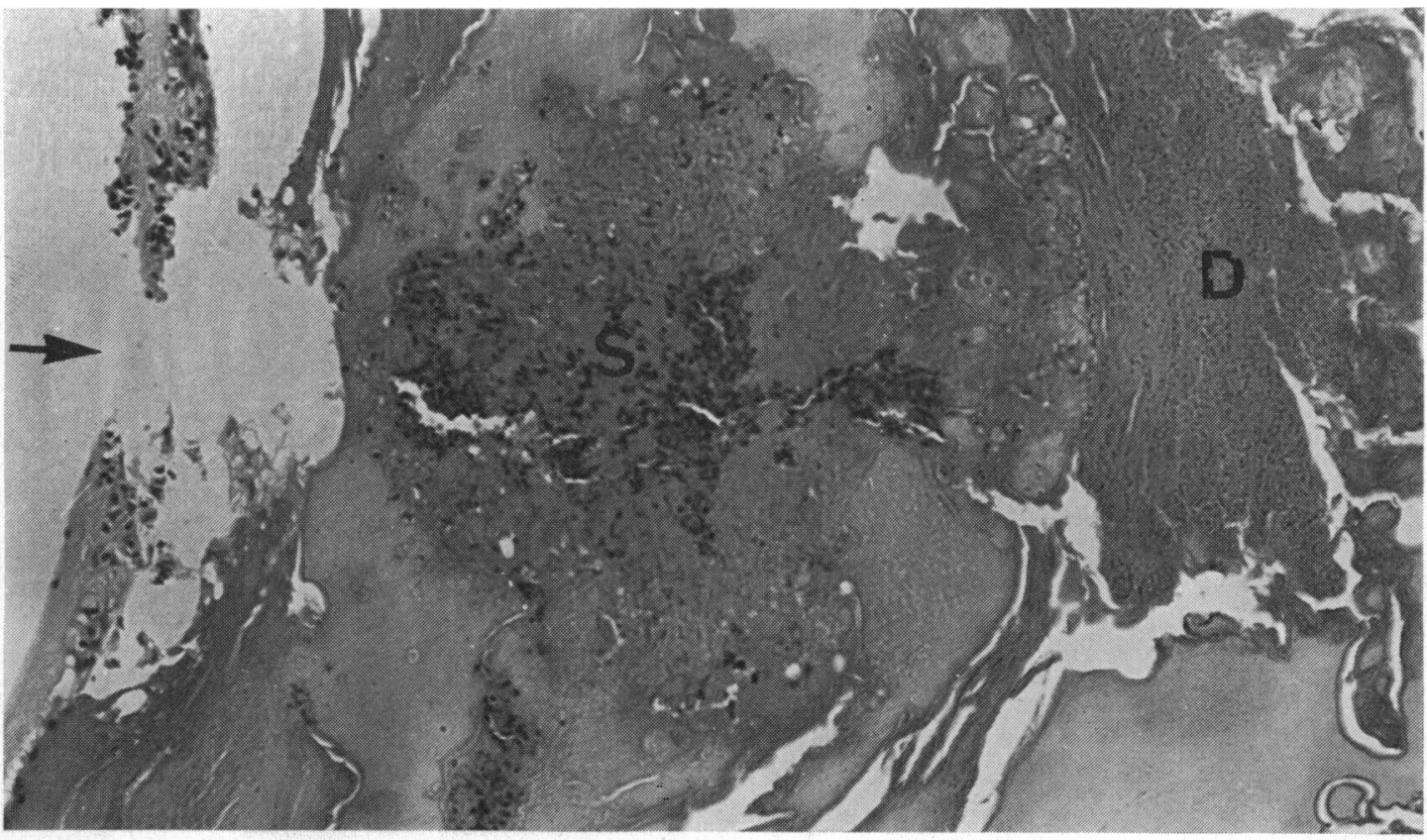

FIG. 8 Left eye. Equatorial region of lens. Two masses of microsporidia lie within cortical cataract. Inflammatory cells have invaded the more superficial mass (S), entering through a rupture in capsule (arrow). The deeper mass (D) is free from inflammatory cells suggesting that capsule rupture was due to a secondary inflammatory invasion rather than $a$ portal of entry for parasities. Haematoxylin and eosin. $\quad \times 180$ 


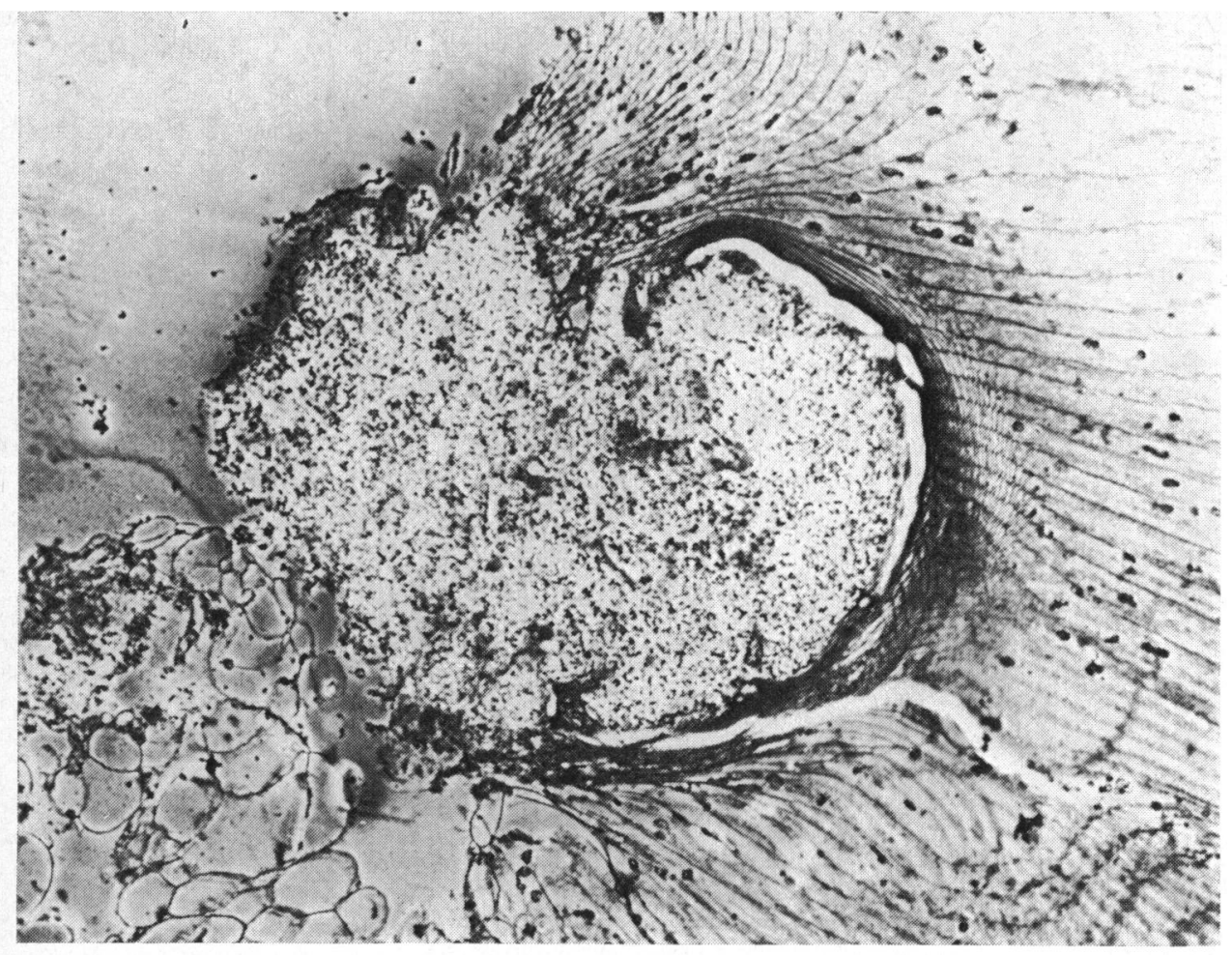

FIG. 9 Left eye. Margin of lens nucleus showing a mass of microsporidia lying in cataractous semi-fluid lens material. Grocott-Gomori. $\times 280$

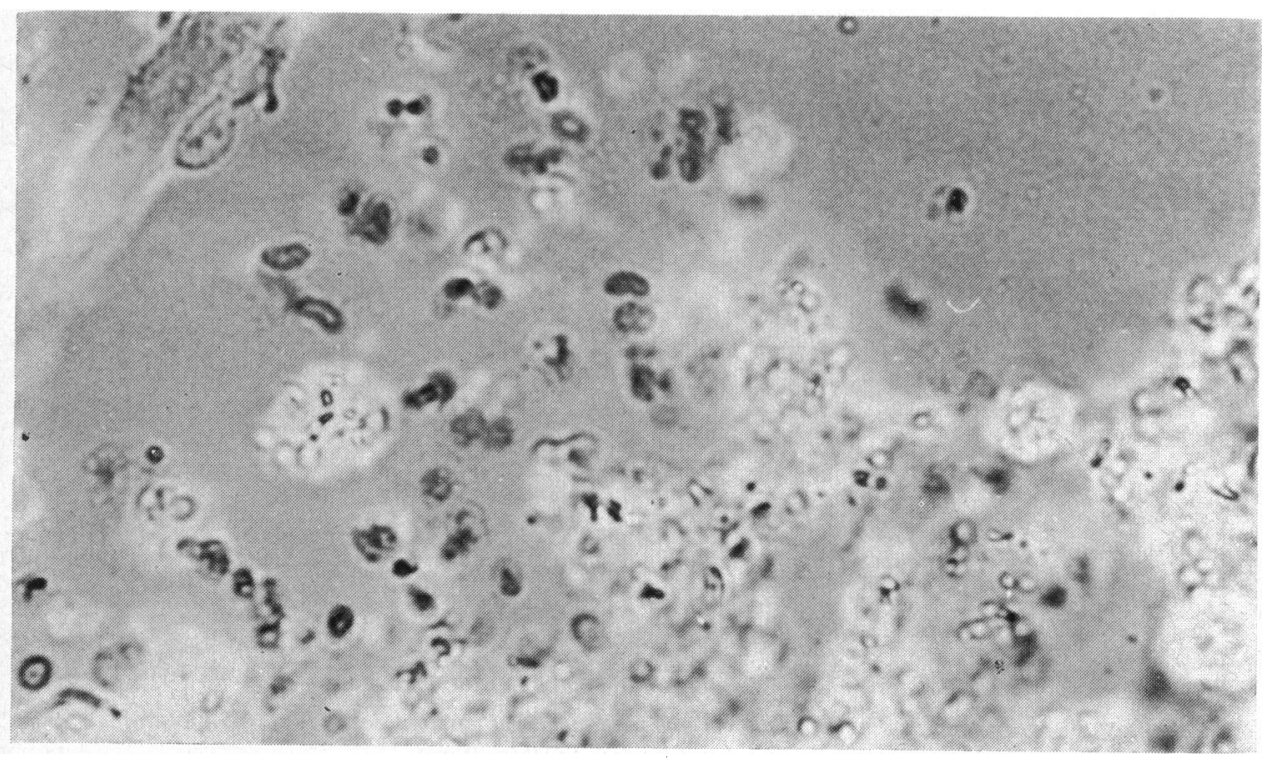

FIG. 10 Left eye. Numerous microsporidan spores seen within the lens. The characteristic oval, round and comma shapes of the argyrophilic and refractile spore capsules can be seen. Grocott-Gomori. $\times 1800$ 
and size of microsporidia and argyrophilic granules are often seen in normal and cataractous lenses as fixation artefacts or pathological break-down products. Great care is needed in differentiating them from degenerate microsporidia especially as the two were seen to occur together in this rabbit's lenses. The vacuoles, some of which are due to shrinkage of lens interlocking processes and especially resemble microsporidia (Fig. I6), may be differentiated by their variability in size and their failure to take up silver stains. The ultrastructural appearances are the final arbiter and in the case here reported are strongly suggestive of microsporidia as illustrated by Lom and Vavra (1963a, b) and Sprague and Vernick (1968) and closely resemble those described for Encephalitozoon cuniculi (Petri and Schiødt, 1966; Margileth and others, 1973). Complete proof would have been the unequivocal demonstration of the polar filaments, whereas in our electron micrographs these could be only vaguely discerned. Nevertheless, we believe the correct diagnosis to be bilateral cataract due to Encephalitozoon cuniculi with reactive anterior uveitis and retinal perivasculitis and will proceed to the discussion on the basis of this conclusion.

\section{Discussion}

This example of bilateral cataract due to encephalitozoonosis in a spontaneously infected laboratory rabbit raises a number of interesting points. The fact that it has only now been recognized suggests that it is probably a rarity, and the bilateral involvement without injury to the ocular envelope indicates an origin from systemic infection, but as this diagnosis was not suspected clinically other organs were not examined. Since it has been reported that microsporidia are apparently unable to penetrate Descemet's membrane (Ashton and Wirasinha, 1973) it might be inferred that a mature lens capsule would also form a barrier, suggesting that the microsporidia gained entry to the lens at an early stage of intrauterine development before the capsule was fully formed (the two small ruptures seen only in the lens capsule of the left lens were likely to be due to a secondary inflammatory invasion). Vertical transmission of encephalitozoon is thought to occur (Levaditi, Nicolau, and Schoen, 1924; Perrin, 1943; Nelson, 1967) and has been strongly supported experimentally (Hunt, King, and Foster, 1972).

The equatorial preponderance of the infection and the associated degenerate epithelial cells suggest that the parasites probably invaded the lens epithelium in this region, as actually observed in some sections, and were carried into the lens as the fibres developed. Here it is improbable that the microsporidia would long survive since they are very simple organisms devoid of organelles and containing little besides the genome, which is injected via the filament into the host cell, so resembling viruses (phages) in this respect rather than protozoa (Sprague and Vernick, 1968). Unless the enzymes of biological oxidation are located in the spore membranes (Liu, 1973, 1975) microsporidia would seem to be entirely dependent upon the metabolism of fully functional cells, which the epithelial cells of the lens cease to be as they transform into fibres with loss of nuclei and organelles.

An intriguing question is why the parasites were found only within the lens; the inflammatory reaction outside the capsule in the anterior and posterior segments probably resulted from diffusion of a toxin from the intralenticular colonies. Such a selective affinity for lens epithelium, however, is not unique as it is seen also in many cases of the rubella syndrome where cataract may similarly be the

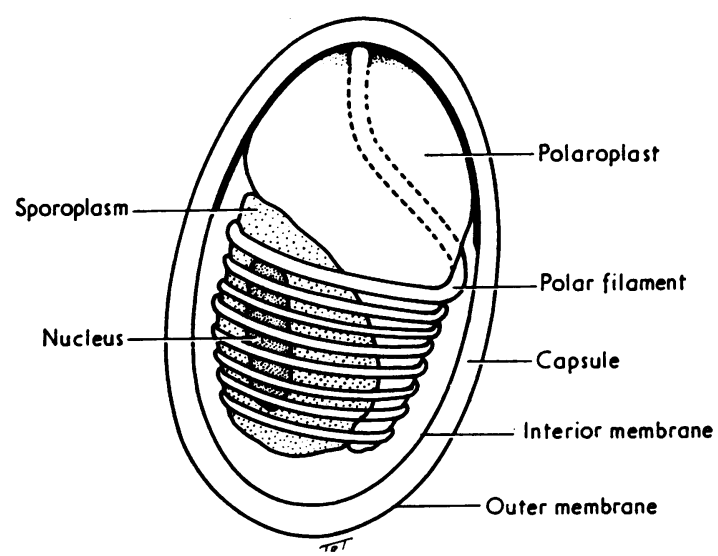

FIG. I I Diagram of the fine structure of a microsporidan spore (after Kudo and Daniels, 1963) showing thick capsule and characteristic tubular coiled polar filament passing through polaroplast, which may appear laminated, gramular, or vacuolar and which is responsible for ejecting the filament. A nucleus lies within the sporoplasm

predominant or only ocular abnormality. Another explanation could be that the microsporidia within the lens as opposed to those without, are protected from immune reactions.

Encephalitozoon cuniculi bear a close resemblance to Toxoplasma gondii and, although taxonomically not closely related, they can readily be mistaken for each other, a point of great importance in microscopical differential diagnosis (Margileth and others, 1973). Since both these parasites may be transmitted transplacentally the question arises whether Toxoplasma could similarly be directly responsible for cataract. The lens is usually undamaged in ocular toxoplasmosis and in cases where cataract occurred it was regarded as secondary to the inflammatory reaction (Dekking, 1949; Glees, 


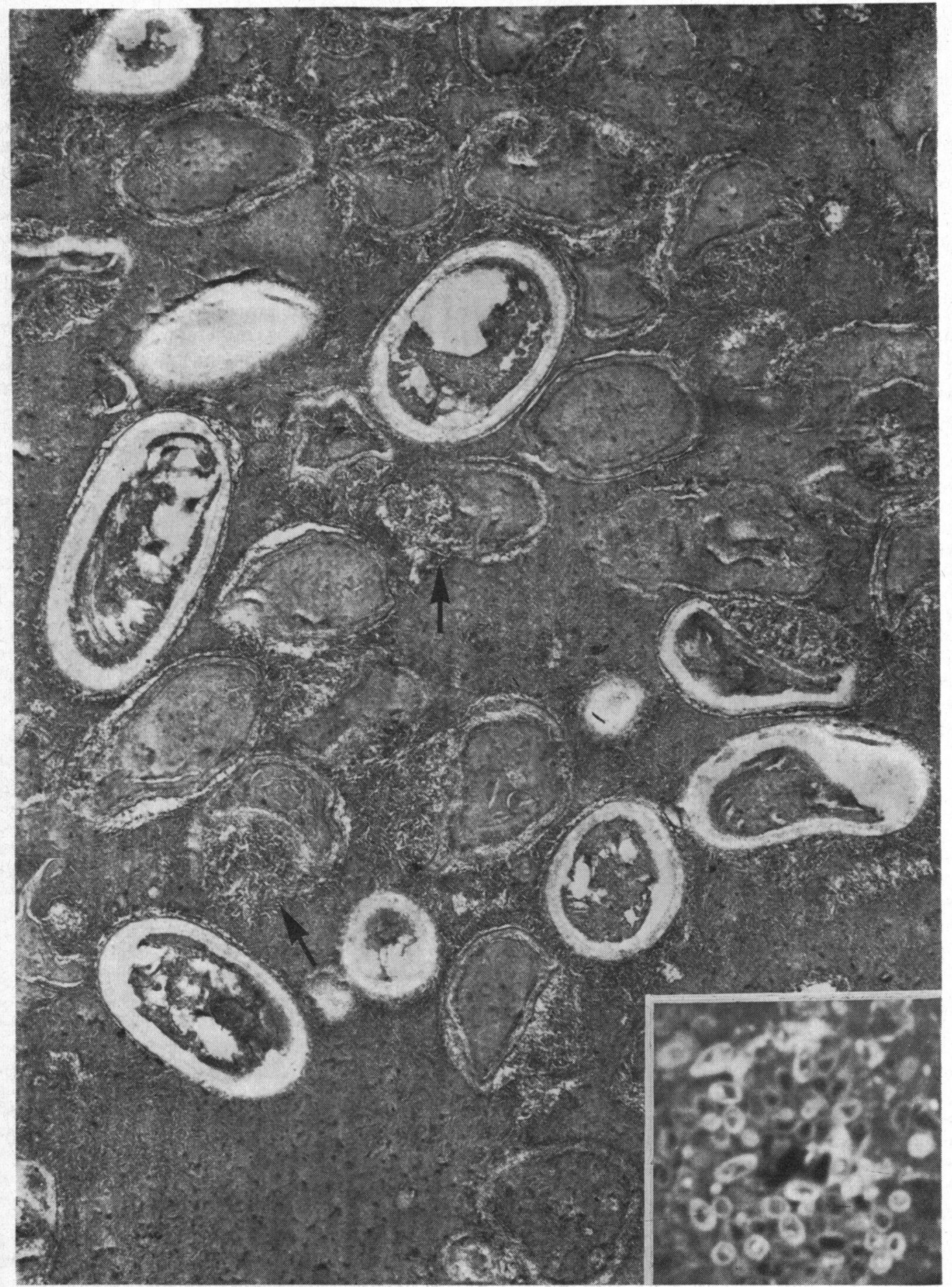

FIG. 12 General view of microsporidia in left lens showing a few vacuolated and thickly encapsulated mature spores and numerous sporonts lying in homogeneous matrix containing coarsely granular material which is also seen within the sporonts (arrows). Electron micrograph. $\times_{1} 5000$. Insert shows light microscopy of epon section of this area. $\times 2880$ 


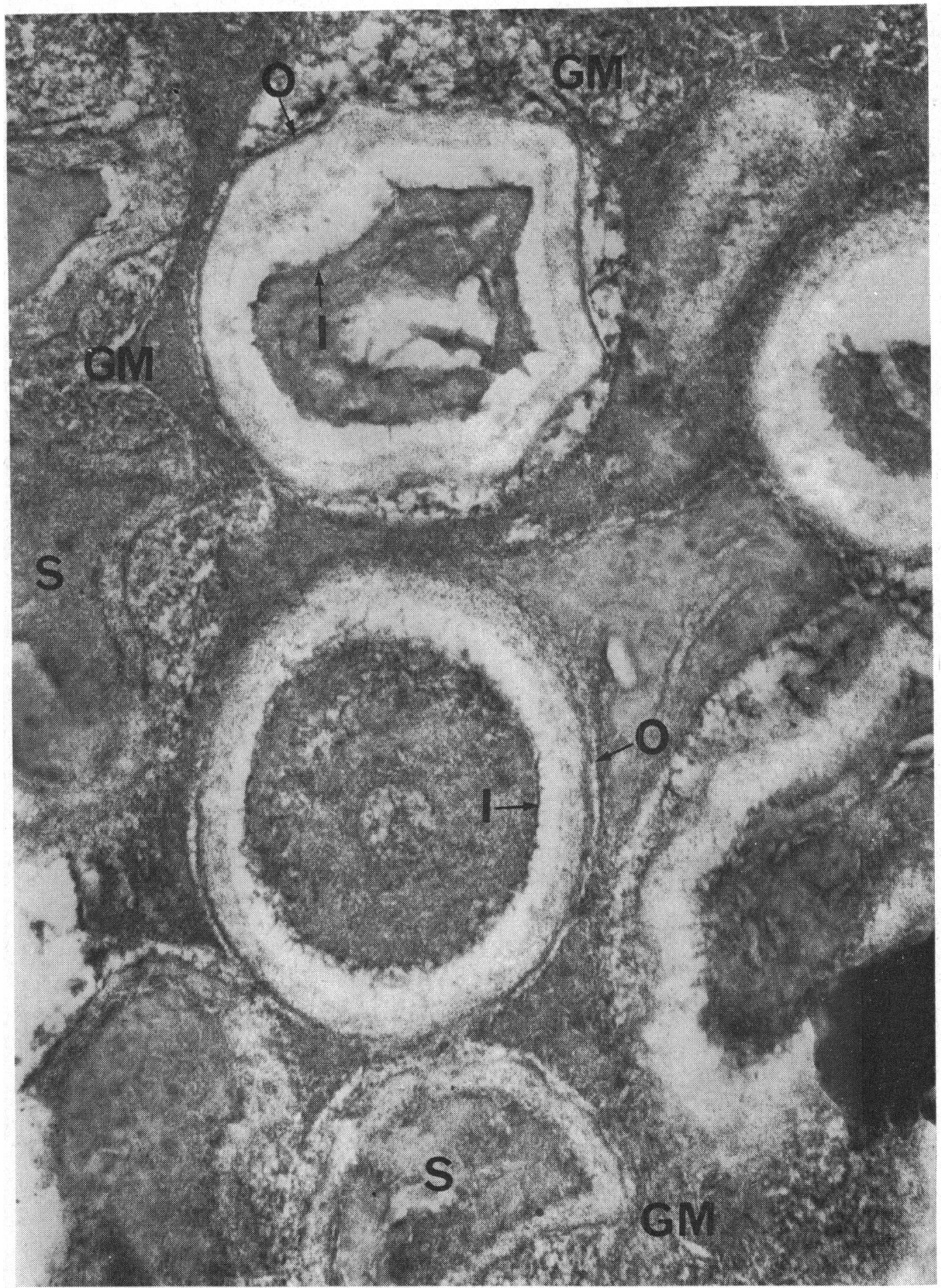

FIG. 13 High power view of microsporidia. Fully mature spores show thick electron lucid capsule with its inner (I) and outer (O) membranes. Coarse granular material (GM) is present within and around sporonts (S) which show earlier stage of encapsulation. Electron micrograph. $\quad \times 48000$ 




FIG. 14 Another area showing a spore in which laminated polaroplast (PP) might possibly be discerned anteriorly and indistinct circular and convoluted profiles $(P F)$ may represent coiled polar filament. Electron micrograph. $\times 48000$ 

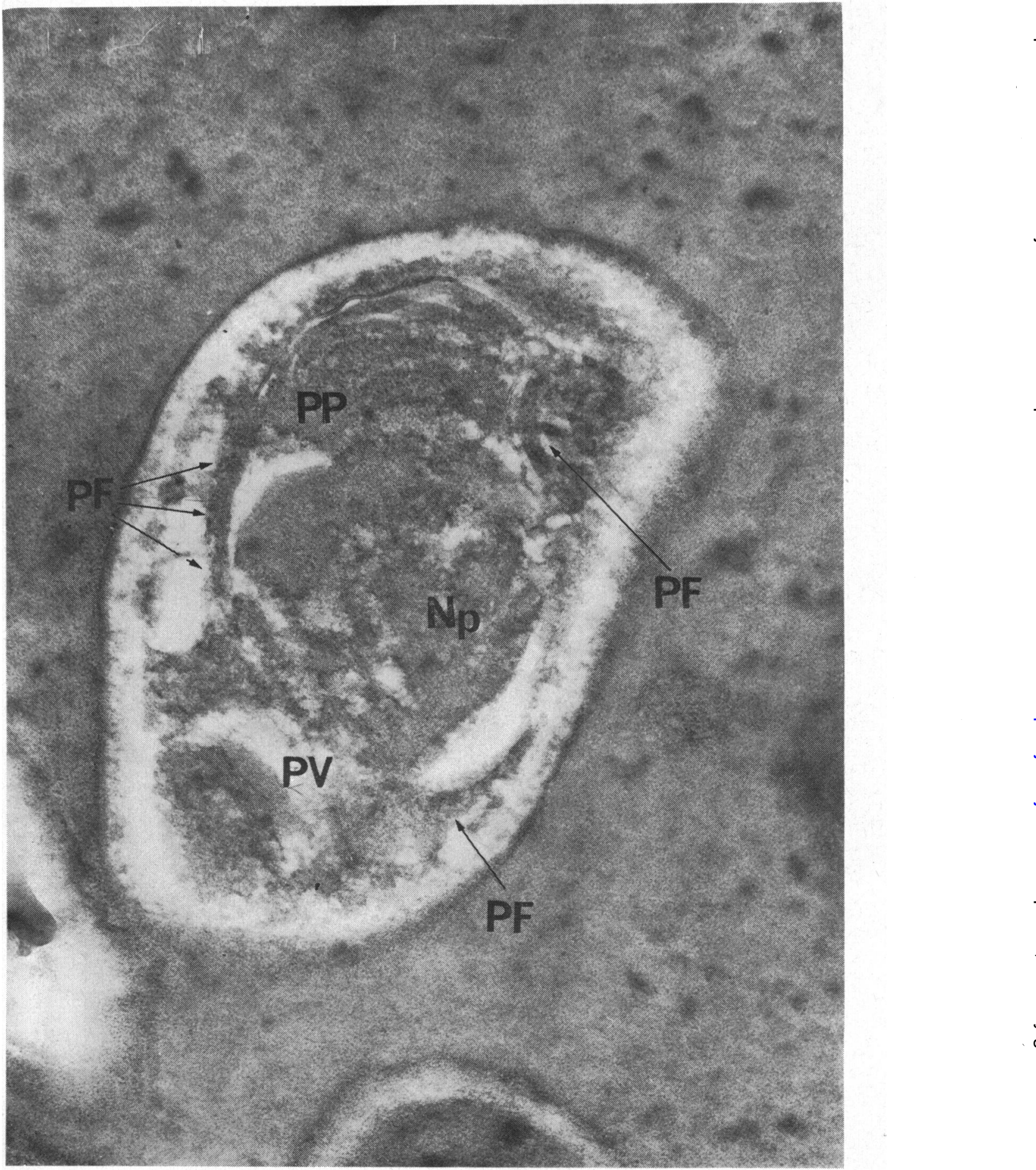

FIG. I5 Higher power view of a microsporidan spore. Laminated polaroplast (PP), fragments of polar filament $(P F)$, nucleoplasm $(N p)$ and posterior vacuole may possibly be discerned (PV). Electron micrograph. $\times 70000$ 


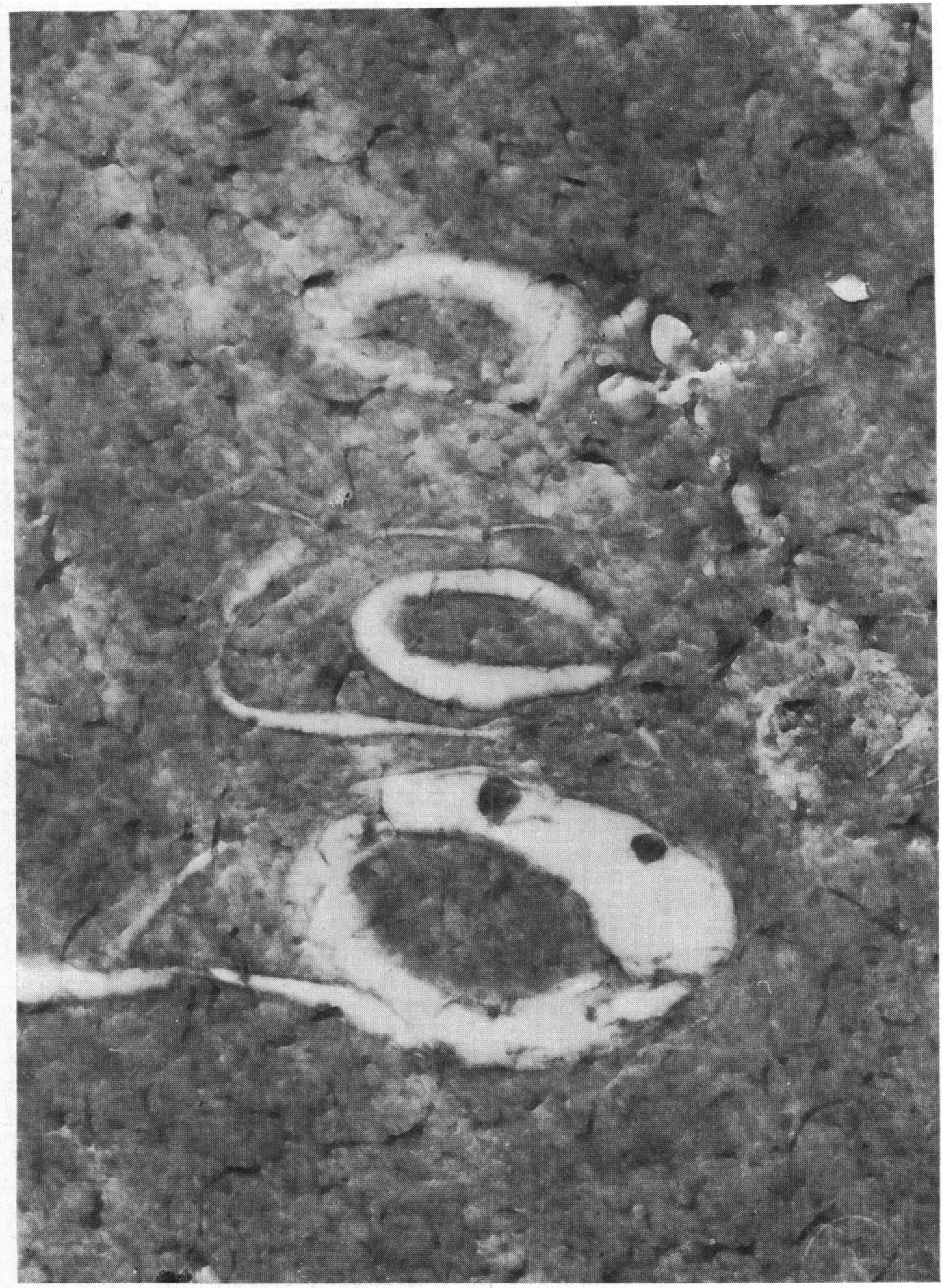

FIG. I6 Cataractous lens showing profiles superficially resembling microsporidia, but which are of variable size. The pseudocapsules are due to gross widening of intercellular space between a lens cell and interlocking processes of adjacent cell. Electron micrograph. $\times 33000$ 
1953; Lavat, 1953): in rats where congenital cataract was the only manifestation of toxoplasmosis it was attributed to toxins produced by the parasites (Giroud, Giroud, and Martinet, 1954). There is only one report in the literature suggesting direct invasion of the lens: Ourth (1971) claimed to have demonstrated Toxoplasma gondii in 30 per cent of a series of cataractous human lenses using the direct fluorescent antibody technique. This question was carefully re-examined by Davies, Fleck, and Rahi (1973) who could not agree with Ourth's interpretation, believing that the particles he described were fragments of lens epithelium disrupted during homogenization. These investigations, however, were mainly concerned with senile cataract, so that whether or not protozoa play any direct role in the aetiology of congenital cataract in man, although extremely unlikely, still remains unknown.

\section{Summary}

Bilateral cataract due to a microsporidan believed to be Encephalitozoon cuniculi (also called Nosema cuniculi) is described as an incidental finding in a laboratory rabbit. The route of infection and the significance of the findings are discussed. This is apparently the first report of cataract due to this cause.

Our thanks are due to Miss E. Robins and Mr G. E. Knight, Mr R. Alexander and Mr A. I. Ahmed for technical assistance and to Miss E. FitzGerald for secretarial help.

\section{References}

AShton, N., and Wirasinha, P. A. (1973) Brit. F. Ophthal., 57, 669

basson, P. A., McCully, R. M., and Warnes, w. E. J. (1966) F. S. Afr. vet. med. Ass., 37, 3

CALI, A. (I97I) In 'Proc. IV Int. Colloq. Insect Pathol', with Soc. for Invertebrate Pathology, College Park,

Maryland, August 1970, pp. 431-438. United States Dept. of Agriculture

DAVIES, P. D., FlECK, D. G., and RAHI, A. H. S. (1973) Brit. Y. Ophthal., 57, 7 I 7

DEKKING, H. M. (1949) Ophthalmologica (Basel), I17, I

GIROUd, P., Giroud, A., and Martinet, M. (1954) Bull. Soc. Path. exot., 47, 505

GLEES, M. (1953) Ophthalmologica (Basel), r26, 36r

HUNT, R. D., KING, N. W., and FOSTER, H. L. (1972) F. infect. Dis., 126, 212

KANGAS, J. (1971) Personal communication. Quoted by Nordstoga, 1972

KUDo, R. R., and DANIELS, E. W. (1963) F. Protozool., IO, 112

KULL, K. E. (I97I) Personal communication. Quoted by Nordstoga, 1972

LAINSON, R., GARNHAM, P. C. C., KILLICK-KENDRICK, R., and BIRD, R. G. (1964) Brit. med. $\mathfrak{\text { ., } , ~ 2 , ~} 470$

lavat, J. (1953) Arch. Ophtal. (Paris), 13, 252

levaditi, C., Nicolau, s., and schoen, R. (1923) C.R. Soc. Biol. (Paris), 89, 984

$\longrightarrow$, and (1924) Ibid., 90, 194

LIU, T. P. (1973) Tissue and Cell, 5, 315

(1975) Ibid., 7, 6r 3

lom, J., and vavra, J. (1963a) Acta Protozool., r, 8r

$\longrightarrow$, and $\longrightarrow$ (1963b) Ibid., 1, 279

MARgileth, A. M., STRANo, A. J., CHANDRA, R., NEAfie, R., BlUM, M., and McCully, R. M. (1973) Arch. Path., 95 , I45 MATSUBAYASHI, H., KOIKE, T., MIKATA, I., TAKEI, H., and HAGIWARA, S. (1959) Ibid., 67, I8I

NELSON, J. B. (1967) F. Bact., 94, I340

NORDSTOGA, K. (1972) Nord. Vet.-Med., 24, 2 I

OURTH, D. D. (1971) Brit. F. exp. Path., 52, 276

PAKeS, S. P. (I974) In 'The Biology of the Laboratory Rabbit', ed. S. H. Wesibroth, R. E. Flatt, and A. L. Kraus,

p. 273. Academic Press, New York

PERRIN, T. L. (1943) Arch. Path., 36, 559

PETRI, M. (1969) Acta path. microbiol. scand. (suppl. 204), 52

, and SCHIøDT, T. (1966) Ibid., 66, 437

Plowright, w. (1952) F. comp. Path., 62, 83

SCHUSTER, J. (1925) Klin. Wschr., 4, 550

ShaDdUCK, J. A., and PAKeS, S. P. (197I) Amer. F. Path., 64, 657

SPRAGUE, v., and VERniCK, S. H. (r97I) F. Protozool., 18, 560

WEISER, J. (1964) Parasitology, 54, 749

WRIGHT, J. H., and CRAIGHEAD, D. M. (1922) F. exp. Med., 36, I35 